\title{
Methods of Azimuth Determination at a Magnetic Repeat Station: A Comparison
}

\author{
Luiz Muniz BARRETO* \\ Emeritus-Professor, Observatório Nacional, Brasil
}

(Received December 15, 1995; Revised August 14, 1996; Accepted August 17, 1996)

\begin{abstract}
The determination of geographic azimuths is an essential step in field magnetic surveys. In spite of the relatively low precision required for declination values, it is strongly recommended that those true azimuths should be measured with an error in the order of $0.1^{\prime}$ to avoid contamination of desired magnetic values. The applicability and ease of use, as well the deficiencies of the various methods of azimuth determination must be considered in the light of the different field work conditions encountered during repeat station surveys. In general, four classes of methods could be considered: geodetic, astronomical, use of a gyro-theodolite and use of a GPS system. The strengths and weakness of each of these methods are discussed and a comparison between them is made. Notwithstanding a possible worldwide interest of this subject, a special emphasis is given to magnetic repeat station work in developing countries. As a conclusion, we could say that the most suitable method for azimuth determination at a magnetic repeat station strongly depends on regional conditions. For developing countries (latitude range between $30^{\circ} \mathrm{N}$ and $30^{\circ} \mathrm{S}$ ), mainly for Latin American countries, the gyro-theodolite method proves to be very effective at the present time.
\end{abstract}

\section{General Considerations}

In spite of the interest to present this subject in its global aspects, this paper gives special emphasis to magnetic repeat station work in developing countries. In fact, if we take a look at the geographic distribution of magnetic observatories, we understand the importance of repeat station networks in the areas where such observatories are very scarce, as they are in developing countries.

Essentially, a repeat station, even a regional repeat station network cannot carry out all functions of a well operated observatory (Fukushima, 1995). The study by ground based measurements of some important geomagnetic phenomena, such as high frequencies and seasonal variations, requires a continuous recording of the geomagnetic field. The usual practice for repeat station reoccupations, a measurement each 5 years (Wienert, 1970) is not sufficient to furnish all desirable information.

In developing countries the average distance between magnetic observatories is many thousands of kilometers, which, given the enormous oceanic gaps in the observatory network surrounding these countries provokes a very bad situation. According to the statistical analysis of Gama (1969) for South America, that distance should be lesser than $500 \mathrm{~km}$, specially near the Equatorial Electrojet (EEJ), and the South Atlantic Geomagnetic Anomaly (SAGA).

However, ideal conditions are the enemies of possible solutions, and we must be satisfied with the traditional uses of repeat station data, namely secular variation studies (Gama, 1969) and magnetic field modelling.

From the above considerations we conclude that a great part of ground based geomagnetic data comes from repeat station networks for a large area of the planet. These circumstances impose a strong responsibility for accurate field work at repeat stations, as well as for carefully observing points (Barreto, 1990).

*Visiting-Professor, Universidad Nacional Autónoma de México. 
Since the year 2634 bC (Fukushima and Barreto, 1995) the traditional application of Geomagnetism to orientate a land or sea journey gives a great importance to geomagnetic declination. A large historical series of declination data for many parts of the Earth permits the extension of D-secular variation studies to many centuries ago. This fact shows the importance of such measurements and, in consequence, of accurate azimuth determinations.

Although it is not advisable to extend accuracy beyond the limits of efficacy, the determination of the true or geographic azimuths should be made with a precision better than, or at least equal, to the required geomagnetic values, in order to avoid spurious contamination.

In all cases, the particular conditions and difficulties encountered in field work must be considered. Time is an important factor, both for its financial aspects and also for the convenience of concentrating the measurements in a reasonable period of time, to facilitate the reduction to a specific epoch. A previous estimate of secular variation, considered as linear between two consecutive epochs, is a good help.

Equipment cost is another important factor to be considered, but it must be compared with the operating costs in field. Sometimes, high initial equipment cost could be strongly reduced in following years during subsequent field campaigns.

We must also be attentive to the portability (both weight and volume) and the reliability of equipment, two essential characteristics in remote areas with difficult logistic conditions. The 5 years period used to reoccupy a network of repeat stations suggests a previous knowledge of azimuths at each station to save time and money. For this reason it is advisable to record properly all observed data at each station, including the azimuths of a reasonable number ( 3 or 4 ) of distant reference marks, to avoid a possible loss of some of them (Wienert, 1970; Newitt et al., in press).

Considering the points set out above, there are four general methods of azimuth determination which may be suitable for magnetic repeat station work: Geodetic methods, Astronomical methods, Gyrotheodolite methods and GPS methods.

\section{Geodetic Methods}

In many regions, largely in the northern hemisphere, the existence of a network of trigonometrical points, established by geodetic methods and maintained on a governmental basis permits the determination of azimuths with an accuracy of $0.1^{\prime}$, provided that good geodetic data are available.

Generally, this method is not used in developing countries due to the scarcity of confident geodetic networks, but it has been used occasionally in some parts of the Brazilian coastal region.

\section{Astronomical Methods}

Astronomical methods (sun or star observations) are well known, and they have a long tradition of use worldwide. They are well explained in many books on field astronomy (Liais, 1867; Caspari, 1889; Mattos, 1940; Nassau, 1948; Roelofs, 1950; Krasavtsev and Khlystin, 1970; Barreto, 1986). Special hints for operation are presented in some of them (Caspari, 1889; Mattos, 1940).

There are a number of different astronomical methods to determine azimuths, such as the "exmeridian altitudes" (or "absolute zenital distances" as it is known in Brazil), the "hour angle", the "circumpolar stars at elongation" and the "equal altitude" methods.

The "ex-meridian altitude method" presents some inconveniences such as a refraction correction. Since the best observing condition is obtained for stars near the first vertical plane (Mattos, 1940), in developing countries (latitudes $30^{\circ} \mathrm{N}$ to $30^{\circ} \mathrm{S}$ ), where the pole is very low above the horizon and the diurnal movements of those stars are near a vertical circle, a small deviation of the secondary theodolite axis from its horizontal correct position provokes a sensible error in azimuth values.

Essentially, the "hour angle" method has the same astronomical basis as the ex-meridian altitude method, but the knowledge of correct local time and latitude are necessary.

In the northern hemisphere the "circumpolar stars at elongation" method is largely used, because the 
existence of Polaris, a bright star near the celestial pole, for which special ephemerides are published. Although Sigma Octantis could be used for the same purpose in the southern hemisphere, at the latitudes of most developing countries in this hemisphere, this star is too low above the horizon.

The "elongation" method is recommended for a great part of the northern hemisphere, but it is not recommended at low latitudes for the reason quoted above. It is important to keep in mind that an elongation point the time variation of the azimuth is near zero $(d A / d t=0)$ and the star image displacement presents some indetermination.

An interesting paper by Gama (1917) detailed an analytical study of the diurnal movement with criticisms about the most common methods of field astronomy, and in particular on the "elongation" method, as presented above.

The "equal altitudes" method is largely used in Latin America and it is recommended for developing countries. A good theoretical and practical discussion of this method was presented by Amoroso (1928). The main advantages of this method are: no refraction corrections, simplicity of observations, no accurate timing or position tables are required, and no special astronomical knowledge is necessary.

The main weakness of this method is the time required for its use. Usually a period of 3 or 4 hours is necessary to observe the same star at its eastern and western positions at the same altitude. This large working time limits the weather window for observations.

It is easy to understand that star observations are more accurate than solar ones, since stars are point sources and thus very easy to bisect with theodolite cross hairs. On the other hand, it is more difficult to obtain a good contact between the solar limb and a cross hair. For solar observations it is necessary to apply semi-diameter and parallax corrections. For star observations it is possible to use two or more stars for all the methods quoted above, although two or more sun settings could be also made. In spite of a better precision of star observations, the sun has some advantages. A reasonable knowledge of elementary astronomy is required to identify suitable stars and, for some methods, an ephemerides with apparent star positions is needed. This astronomical knowledge is not necessary for the "equal altitude" method, both for stars and sun.

Some circumstances in developing countries give some handicap to solar observations. In almost all tropical regions, specially during some seasons, the diurnal weather is generally better than the nocturnal weather. Sometimes a haze dims a 2 nd. magnitude star. On the other hand, a four hour interval centered at noon is usually clear in those regions. It is important to consider that magnetic measurements are not recommended in the time around local noon, since the geomagnetic daily variation has its greatest value during this time (Barreto, 1992). Thus azimuth determination is a useful task to be performed around noon. Early morning and/or late afternoon should be used for magnetic observations, because the reduction to the "flat" or midnight field is easier for observations made at these times on quiet or regular days (Barreto, 1995).

The use of star observations furnishes an azimuth value with a standard deviation of 1 " if a good astronomical theodolite is used (Mattos, 1940). On the whole, solar observation accuracy furnishes an average error of $5^{\prime \prime}$, with an astronomical theodolite, or $0.1^{\prime}$ if a DI-magnetometer theodolite is used, these are acceptable values for magnetic field work.

Actually, with the wide spread use of the theodolite mounted DI-fluxgate magnetometer there is the possibility of using the same equipment for azimuth determination. This instrument has an accuracy of $0.1^{\prime}$. This double utilization for azimuth and magnetic measurements saves space and equipment weight, important conditions for field work.

Finally, from the preceding statements we conclude that, in spite of their clear advantages, the astronomical methods present two major inconveniences. The necessity of clear skies can be a major problem, particularly in tropical countries or in some regions during raining seasons, when the observer could be obliged to spend several days waiting for clear skies suitable for astronomical observations. Post observation calculations are extensive, particularly with the "hour angle" method, though portable computers ease most of the burden. 


\section{Gyro-Theodolite Methods}

The gyro-theodolite is a dynamically-functioning measuring instrument that was designed to be used on land surveys for fast azimuth determinations.

The ease of use and the short time of operation are the best advantages of these methods for magnetic field work. On average, the azimuths of 3 or 4 targets could be obtained in less than 2 hours, with an accuracy of $0.1^{\prime}$. No special theoretical knowledge is necessary to operate a gyro-theodolite and one week of instruction and practice is usually sufficient to train a good technician to use the instrument competently.

The gyro-theodolite increases the total weight of the survey equipment by about $5 \mathrm{~kg}$, a relatively small addition to the overall weight, usually over $100 \mathrm{~kg}$, including tents and spare parts. The same tripod required for the DI-fluxgate can also be used for the gyro. In spite of these advantages, the gyro is not suitable at latitudes greater than $50^{\circ}$, because it presents a setting instability that increases with latitude. On the other hand, it is no longer built by traditional European manufacturers (Wild, for instance), but it could be found in Japan and Russia.

The general and theoretical bibliography on the gyroscope is very large (Gray, 1959), and besides the classical treatises on Euler's problem, there are some specific publications dealing with the gyrotheodolite (Machover, 1960; Torochkov, 1970). The best way to become familiar with the use and operation of the gyro-theodolite is to read the manufacturer's manual (Wild, 1972) or instruction manuals prepared by experienced users (Gualda, 1970).

Essentially, a gyro-theodolite consists of a medium precise theodolite ( 0.1 ' accuracy), a gyroscope system firmly coupled to the theodolite, an electric power (a common car-battery) and control system.

During operation, the gyroscope is suspended above its center of mass on a thin tape, like a plumb bob, and its spin axis is thus led horizontally by the force of gravity. The gyro-rotor, spinning at about $20,000 \mathrm{rpm}$, tries to maintain its initial spinning plane in space, owing to its great inertia moment and its large rotational speed. However, as the gyro attachment is earthbound together with the theodolite and tripod, it is pulled out of its original spinning plane by the Earth's rotation.

The gravity-influenced gyro reacts, and its spin axis precesses about the plumb line until it takes up its position in the meridian plane. In this position, the gyro spins in the same way as the Earth, from the west to the east, and there is no more interference. However, in consequence of its mass inertia, the gyro axis itself does not stop exactly in the north-south position (meridian), but it oscillates about the meridian plane between two "reversal points".

In order to obtain the best meridian reading on the horizontal circle, two methods can be used: reversal points or meridian transit timing.

In the first case, the average of a number of readings, at left and right reversal points, in the horizontal circle is the most accurate value of the meridian direction.

In the transit method, various instants of a fiducial mark transit over a central reference mark are noted. Some intervals between two successive transits are averaged out and multiplied by an instrumental constant, to obtain the correction to be applied to the circle reading at an approximate meridian position to yield the circle reading of the true meridian.

For both methods it is necessary to first align the spinning-axis of the gyro close to the meridian. In order to obtain this condition the so called "quick method" is used. After a crude preorientation (by a compass or a good chart) this fast procedure permits to obtain the approximate meridian direction within $10^{\prime}$. In fact, it is a shortening of the reversal-points method where only two horizontal circle readings are to be made.

For the reversal points method, a pre-orientation within $2^{\circ}$ of meridian is sufficient, but for the transit method an accuracy of $10^{\prime}$ reduces the time of operation considerably.

At a first glance, the transit method seems to be more complicated, mainly for the necessity to obtain an instrumental constant and to record intervals of time. In spite of this it is a more rapid and precise method 
than the reversal points method. In practice, it proves difficult to read the horizontal circle for each reversal point.

The determination of the instrumental constant required for the transit method is an easy operation, and can be made before a campaign provided the field work is limited to a latitude range of $10^{\circ}$, or can be repeated in the field if such limit is surpassed. Analysis of the field work in Brazil shows that the variation of the constant for a latitude range of $38^{\circ}$ furnishes a change of only $0.1 \%$, a small value, if a good pre-orientation is obtained.

For these reasons, the transit method was adopted by the National Observatory of Brazil by the late Gualda (1970). After a careful study of its feasibility, precision and advantages over the other methods of azimuth determination was find out. More than 500 measurements were made with good results at 120 magnetic repeat stations in the latitude range (from $5^{\circ} \mathrm{N}$ to $5^{\circ} \mathrm{S}$ ). A standard deviation of $0.1^{\prime}$ was derived of those measurements.

At some of those repeat stations, the astronomical "equal altitude" method(sun and star observations) was performed, for comparison. The operating time was truly in favor of the gyro-theodolite method.

It is important to keep in mind that a very accurate determination of azimuth must be performed to calibrate gyro-theodolites before all field"campaigns. Such determination must be made with an accurate astronomical method, by using stars. It is performed at the observer headquarters with all requirements and facilities, during clear nights, and the standard deviation is $1^{\prime \prime}$ or better. This operation is necessary before the first gyro-theodolite campaign and the time for a gyro test in subsequent field works is made in few minutes.

\section{GPS Methods}

The NAVSTAR-GPS (Navigation System with Time and Ranging-Global Positioning System) is a satellite-based system which provides precise 3-dimensional position and timing information for adequately equiped users. This system of ground positioning is available on a worldwide basis 24 hours a day, and it is independent of meteorological conditions.

It was primarily designed for military purposes to accurately determine position, velocity and time of targets on a continuous basis. A few years after this initial purpose, the GPS system was adopted to be used in geodesy and geodynamics to furnish geodetic precise positions.

The rapid technical improvement of the GPS system resulted in the increase of precision, avaliability and a notable decrease in cost. Its applicability has been extended to other areas including navigation, and relative motions of tectonic plates.

There is no tradition of the use of GPS for azimuth determinations at geomagnetic repeat stations, but in view of its fast technical development and lack of geographical limitations, it has great promise for use in magnetic repeat station work for the years ahead.

However, some considerations must be given to its geomagnetic uses, such as the small required accuracy $\left(0.1^{\prime}\right)$, the distance between the station and the targets, usually between 1 to $5 \mathrm{~km}$, the necessity of two observing points, the local topography and the equipment cost.

From a broad viewpoint two general classes of GPS receivers could be considered: the micro or handheld receiver and the precise and portable GPS station. Differences in prices, sizes, weights, and precisions of these two classes are considerable. A hand-held unit costs a few hundred US dollars, while a GPS station can costs between 20 to 40 thousand US dollars.

With a hand-held receiver, according to manufacturer's manuals (Trimble, Ashtech, Garmin) a geographic position could be determined with an accuracy of $15 \mathrm{~m}$ in a few seconds, a very optimistic information. Generally, the degrading of the GPS signal limits accuracy to about $100 \mathrm{~m}$, horizontally. However, even given the optimistic hypothesis of $15 \mathrm{~m}$ precision it is not sufficient to determine an azimuth with the required accuracy $\left(0.1^{\prime}\right)$, since the distance between the instrument and the target is usually less than a few kilometers. On the other hand, with a good pair of GPS stations, it is possible to obtain a precision of a few centimeters in all three dimensions in a couple of hours. 
There are many books and papers on GPS theory and practice, and the few examples quoted in the references (King et al., 1985; Seeber, 1988; Simon, 1991; Letham, 1995; Van Sicke, 1995) are only a small sample on this subject. For this, a detailed description of this instrument is not necessary here. Notwithstanding such references, some general aspects of GPS operation would be useful for a comparison with the other methods of azimuth determination discussed above.

The GPS system is based on the measurement of the so called "pseudo-ranges" between the user and a set of satellites with known coordinates within a specific reference frame.

In a succinct explanation, a "pseudo-range" is the time shift required to correlate a replica of a code generated in the receiver with the incoming code from a satellite, scaled into distance by the knowledge of the speed of light. In other words, this time shift is the difference between the time of the signal reception, measured in the receiver time frame and the time of emission, measured in the satellite time frame. Theoretically, three range measurements (from 3 satellites) are sufficient to derive the clock offset between the GPS system and the user's clock and thus the horizontal position of the user.

The basic components of a GPS receiver station are: antenna and pre-amplifier; micro-processor for data collection, navigation and control; high-frequency unit for signal identification and processing; control-display unit; high precision oscillator; power supply.

When selecting a GPS surveying system it is necessary to take into account the desired accuracy, the extent of the survey work (in our case, the distance between the stations and the targets) and the resulting relative positioning.

A hand-held receiver could be used for quick surveys, where a relative accuracy of 1:100 is sufficient. In the case of azimuths for magnetic field work, this accuracy is very poor, because we could expect an error greater than $20^{\prime}$ over the usual distance between a repeat station and a reference mark.

However, a hand-held GPS receiver is a very useful piece of equipment to obtain the geographic position of a repeat station with acceptable precision. It could also be used to obtain a good pre-orientation for the application of the transit method with a gyro-theodolite. A hand-held receiver is a cheap and small instrument, which is indispensable during geomagnetic field work.

For geodesy and geodynamics and, in particular, for geomagnetic field work, two or more GPS stations are required to obtain the necessary accuracy. When two or more receivers are used, the method is called "relative" or "differential" positioning and, in this case, the same satellites are tracked simultaneously by at least two receivers, thus allowing the removal to a great extent of the effects of selective availability and ionospheric delays.

In a crude speculation, we could consider that a pair of GPS stations would furnish acceptable values for the azimuths. In accordance with the nominal specifications of an usual commercial set, from a differential measurement it is possible to obtain an accuracy of $5 \mathrm{~mm}$ plus one part per million multiplied by the base line length (distance between two GPS receivers). If we consider a typical case, an accuracy of $20 \mathrm{~mm}$ for the horizontal positioning, and a distance of $1 \mathrm{~km}$ for the base line, it would be possible to obtain a standard deviation of about $\mathbf{0 . 1}$ for azimuth values. This is in the limit of acceptibility for magnetic repeat stations.

In case of using a complete GPS double-station for geomagnetic work, it is necessary to consider the high cost of the equipment which can be more than 50 thousand US dollars. In spite of this, it may be possible to share the use of a complete GPS-station if the institution also operates a geodetic or gravity program for which such GPS equipment is used routinely. For well trained technicians, the time of operation may be competitive in comparison with the other methods of azimuth determination.

Other additional problems should be noted, such as the need of an accurately surveyed base station for use in differential GPS mode, the interference of the GPS signal among trees and multi-path effects when the station is near reflective surfaces.

However, owing to the fast technical improvement of the GPS equipment that has occurred over the last few years, it may be possible in the future, that it could be adopted for azimuth determination in geomagnetic field work. 


\section{Conclusions: A Preliminary Comparison}

Trying to compare the advantages and disadvantages of two experimental methods is a difficult task and in this present case, we are faced with many methods. Personal prejudices could produce a misjudgement. It is necessary to consider many factors, such as personal experience, characteristics of the area to be studied (latitude, climatological and topographic aspects), human development of the region and the peculiarities of the institution involved.

In a developed region, where a geodetic network is well established, the geodetic method simplifies the problem. In the northern hemisphere at latitudes higher than $50^{\circ}$ the astronomical methods are the most advisable, specially the elongation method by using Polaris. In spite of the weakness of Sigma Octantis the same procedure could be recommended for the southern hemisphere.

Notwithstanding the good perspectives presented by technical development, today GPS cannot be recommended for an indiscriminate use to obtain azimuths at a magnetic repeat station.

Three years ago we tried to use the GPS method in Central America (Panamá Republic, average latitude of $8^{\circ} \mathrm{N}$ ), owing to the scarcity of clear skies and an ease equipment disposal. The results were not acceptable, probably a question of topographic conditions or a bad use of the system. The astronomical method was used with acceptable results, but with a considerable time loss.

In Brazil, before 1970, only the astronomical equal altitudes method was used. At new repeat stations, a complete azimuth determination must be made, although, for reoccupations, such a procedure was also often necessary because many reference marks were lost due to the development of the country hinterland. For this reason, it was impossible to obtain, in a period of 5 years, the data from 80 repeat stations distributed in an area of 8.5 million square kilometers (Barreto, 1987).

After the introduction of the gyro-theodolite transit method, such a program was possible, with a great economy of time and money. Even the development of the Brazilian hinterland could be considered as a factor for this achievement. In some areas where significant logistic conditions have not occurred, such as the Amazonic Region, the increasing number of new repeat stations may be attributed to the new method of azimuth determination.

Today, about $25 \%$ of the 120 Brazilian repeat stations are located in this difficult region that occupies about $40 \%$ of the total country. This is a significant result, because before 1970 only 15 repeat stations were regularly operated in the Amazonic Region. Costa (1914) in his report about the São Francisco Valley Magnetic Survey, informed that astronomical methods for azimuth determination had taken more than $40 \%$ of the time at each magnetic repeat station.

As a final conclusion, one can say:

(1) In a zone with latitudes between $50^{\circ} \mathrm{N}$ and $50^{\circ} \mathrm{S}$, where developing countries represent the major area, the gyro-theodolite methods are recommended for climatological, economical and logistic characteristics.

(2) Astronomical methods are recommended for latitudes higher than $50^{\circ}$, mainly in the northern hemisphere.

(3) GPS methods for azimuth determination should be considered for the future, owing to their technical development and fast decreasing costs.

The author expresses his thanks to Iris Pereira Escobar (Observatório Nacional, Brasil) for his advice and comments and to J. Esteban Hernández (Universidad Nacional Autónoma de México) for the fruitful discussion.

Thanks are also due to Günther Schulz and A. Lewis for their excellent suggestions to improve this paper.

\section{REFERENCES}

Amoroso Costa, M., O método das alturas iguais, Revista Didática da Escola Politécnica, 11, 41-56, Rio de Janeiro, 1928. Barreto, L. M., Astronomia Geral, 161 pp., Observatório Nacional, Rio de Janeiro, 1986. 
Barreto, L. M., Consideracōes sobre a variacāo secular e o modelamento do campo geomagnético no Brasil, Publ. Especial, Observatório Nacional, Rio de Janeiro, 1987.

Barreto, L. M., Uses and abuses of geomagnetic charts in Latin-America, J. Geomag. Geoelectr., 42. 1103-1106, 1990.

Barreto, L. M., Introducão ás cartas magnéticas, Instituto Panamericano de Geografia e Historia, Panamá, 1992.

Barreto, L. M., Daily variation removal from repeat stations measurements, Reporte Tecnico 95-6, Inst. de Geofisica, UNAM, México, 1995.

Caspari, E., Cours d'Astronomie Practique, Gauthier-Villars, Paris, 1889.

Costa, D. F., Levantamento magnético do Vale do Sāo Francisco, L'Édition d'Art, Bruxelles, 1914.

Fukushima, N., Expectation of all magnetic observatories, ICDC Bulletin, 2, 2-3, Inst. Geof. UNAM, México, 1995.

Fukushima, N. and L. M. Barreto, Geomagnetism and Space Physics, Lectures at the Instituto de Geofísica de la UNAM, México, 1995.

Gama, L. I., $O$ zênite, ponto de discontinuidade, Observatório Nacional, Rio de Janeiro, 1917.

Gama, L. I., Campo magnético normal e sua variacão secular no Brasil em 1965.0, Public. Serv. Mag., 13, Observatório Nacional, Rio de Janeiro, 1969.

Gray, A., A treatise on gyrostatics and rotational motion, Dover Publ., New York, 1959.

Gualda, J., Notas sobre o giroteodolito, Observatório Nacional. Rio de Janeiro, 1970.

King, R. W., E. G. Masters, C. Rizos, and A. Stolz, Surveying with GPS, University of South Wales, 1985.

Krasavtsev, B. and B. Khlyustin, Nautical Astronomy, Mir, Moscow, 1970.

Letham, L., GPS made easy, Mountains, Seattle, 1995.

Liais, E., Traité d'Astronomie Appliqué et de Géodesie Practique, Garnier-Fréres, Paris, 1867.

Machover, C., Basics of gyroscope, J. F. Rider, New York, 1960.

Mattos, A. H., Astronomia de Campo, edited by Liv. Francisco Alves, 2nd edition, Rio de Janeiro, 1940.

Nassau, J. J., Practical Astronomy, McGraw Hill, New York, 1948.

Newitt, L. R., C. Barton, D. Gilbert, and J. Bitterly, Guide for magnetic repeat station surveys, IAGA Working Group 8 (in press).

Roelofs, R., Astronomy applied to land surveying, J. Ahrend und Zoon, Amsterdam, 1950.

Seeber, G., The Global Positioning System, Hanover, 1988.

Simon, S., The Global Positioning System, Burlington, Massachussets., 1991.

Torochkov, V. I., Gyroteodolity, Moscow, 1970.

Van Sickle, J., GPS, a guide for land surveyors, Belmont, Canada, 1995.

Wienert, C. A., Geomagnétic observatories and survey practice, UNESCO, 1970.

Wild-Hererburg, Instructions to Wild GAK1 gyro-theodolite, Zurich, 1972. 